Revue

Revue de l'histoire des religions

de Ihistoire des religions

\title{
Anne-Marie BULTOT-VERLEYSEn, Odon de Cluny, Vita sancti Geraldi Auriliacensis. Édition critique, traduction française, introduction et commentaires
}

Bruxelles, Société des Bollandistes, 2009, XVIII-327 p., $25 \mathrm{~cm}$, (« Subsidia hagiographica », 89), $75 €$, ISBN 978-2-87365-023-0.

\section{Cécile Lanéry}

\section{OpenEdition}

Journals

Édition électronique

URL : http://journals.openedition.org/rhr/7928

DOI : $10.4000 /$ rhr.7928

ISSN : 2105-2573

Éditeur

Armand Colin

Édition imprimée

Date de publication : 1 septembre 2012

Pagination : 427-429

ISBN : 978-2200-92975-0

ISSN : 0035-1423

\section{Référence électronique}

Cécile Lanéry, « Anne-Marie вultot-verleysen, Odon de Cluny, Vita sancti Geraldi Auriliacensis. Édition critique, traduction française, introduction et commentaires », Revue de l'histoire des religions [En ligne], 3 | 2012, mis en ligne le 04 octobre 2012, consulté le 22 septembre 2020. URL : http:// journals.openedition.org/rhr/7928; DOl : https://doi.org/10.4000/rhr.7928

Ce document a été généré automatiquement le 22 septembre 2020.

Tous droits réservés 


\section{Anne-Marie BULTOT-VERLEYSEN, Odon de Cluny, Vita sancti Geraldi Auriliacensis. Édition critique, traduction française, introduction et commentaires}

Bruxelles, Société des Bollandistes, 2009, XVIII-327 p., $25 \mathrm{~cm}$, (« Subsidia hagiographica », 89), $75 €$, ISBN 978-2-87365-023-0.

\section{Cécile Lanéry}

\section{RÉFÉRENCE}

Anne-Marie BUltot-VERLEYSEn, Odon de Cluny, Vita sancti Geraldi Auriliacensis. Édition critique, traduction française, introduction et commentaires, Bruxelles, Société des Bollandistes, 2009, XVIII-327 p., $25 \mathrm{~cm}$, (« Subsidia hagiographica », 89), $75 €$, ISBN 978-2-87365-023-0.

1 Avec ce volume A.-M. Bultot-Verleysen offre à la Vie de saint Géraud d'Aurillac, composée par Odon de Cluny, sa première édition critique. Jusqu'alors, on ne disposait que du texte publié en 1614 par la Bibliotheca cluniacensis, puis repris par les Acta sanctorum et la Patrologie latine. Or, ce texte est précieux à plus d'un titre : il retrace la vie d'un saint laïc, Géraud (855/856 - 909/920), qui fut une figure éminente de l'Auvergne carolingienne; vassal royal, fondateur de l'abbaye d'Aurillac, il était également familier du duc Guillaume d'Aquitaine, et semble avoir bénéficié rapidement d'une réputation de sainteté. Sa Vie (Bibliotheca Hagiographica Latina, $\mathrm{n}^{\circ} 3411$ ) fut composée par Odon, abbé d'Aurillac et deuxième abbé de Cluny (927-942). Ce dernier composa d'abord un sermon en l'honneur du saint (Sermo de festivitate S. Geraldi), avant de rédiger, à la demande de Turpion, évêque de Limoges, et d'Aimon, abbé de Tulle 
(puis de Saint-Martial de Limoges), cette Vita prolixior prima (VPP), que l'éditrice date des années 927-931. Le texte de VPP fut ensuite légèrement remanié, à Cluny, peut-être par Odon lui-même, ou sur ses instructions : la Vita prolixior secunda (VPS), qui résulta de ces retouches, alimenta par la suite la liturgie clunisienne; plus tard, divers abrégés, dont une Vita brevior $\left(V B=B H L\right.$ 3412-14) du $x^{e}$ siècle, prirent le relais dans les légendiers, même si le culte de saint Géraud demeura surtout régional.

2 Parmi tous ces textes, c'est certainement VPP qui présente le plus d'intérêt : de facture élégante, elle est enrichie de très nombreuses citations bibliques et de réminiscences patristiques (Grégoire, Augustin, Jérôme, S. Benoît, etc.) ; on rencontre aussi, çà et là, quelques souvenirs de l'Énéide. Surtout, VPP est basée sur une enquête approfondie d'Odon à Aurillac, ce qui lui confère une crédibilité appréciable. Elle n'en échappe pas pour autant, il est vrai, à la stylisation de rigueur dans le genre hagiographique. Odon a même projeté sur son héros les préoccupations réformatrices qui lui étaient propres, d'autant qu'il avait peine, semble-t-il, à concevoir l'idée d'une sainteté purement laïque : aussi son Géraud apparaît-il bien souvent comme un moine portant l'habit laïc, et non comme un noble carolingien.

3 L'édition critique de VPP est fondée sur les 5 manuscrits complets qui nous en sont parvenus, sur un fragment conservé aux Archives d'Aurillac, ainsi que sur le témoignage indirect de VPS (élaborée, semble-t-il, directement sur l'archétype de VPP). Tous ces témoins sont français, échelonnés $\mathrm{du} \mathrm{XI} \mathrm{I}^{\mathrm{e}}$ au XIV ${ }^{\mathrm{e}}$ siècle ; les autres manuscrits de VPP, incomplets, n'apportent rien de significatif à l'établissement du texte. L'éditrice les avait d'ailleurs précédemment décrits dans un article sur le dossier de saint Géraud ("Sources hagiographiques de la Gaule, IV : Le dossier de Saint Géraud d'Aurillac ", Francia, t. 22, 1995, p. 173-206). Ajoutons en passant que VPP était également connue à Clairvaux : on en rencontre un extrait, passé inaperçu jusqu'ici, dans le légendier de Clairvaux, vers 1170 (Montpellier, Bibl. Fac. Méd., 1, t. 2, f. 202vำ-203r), à la suite de VB (BHL 3412-3412a).

4 L'édition de VPP par Mme Bultot-Verleysen apporte des améliorations substantielles au texte jadis publié d'après divers manuscrits par la Bibliotheca cluniacensis. L'étude des manuscrits, de l'épître dédicatoire et des transitions ménagées par Odon, permettent en outre de revoir la structure de l'œuvre: la Vita composée par Odon n'était pas constituée de quatre livres, mais de deux, suivis d'un Liber miraculorum; le récit de la mort de Géraud (Transitus) ne formerait donc pas un livre autonome, mais plutôt l'épilogue du deuxième livre. Quant au Liber miraculorum, dont l'authenticité a parfois été partiellement discutée, il serait bel et bien de la plume d'Odon, à l'exception des deux derniers miracles, absents dans les manuscrits avant le XII ${ }^{\mathrm{e}}$ siècle, et probablement ajoutés au récit en milieu limousin.

5 Le remaniement VPS, n'a, pour sa part, été conservé que de manière imparfaite. Outre quelques leçons dans des témoins du lectionnaire clunisien, on dispose d'un manuscrit plus complet, mais malheureusement mutilé (Paris, BnF, n.a.l. $2261=C)$; la matière de la Vita Geraldi y apparaît condensée, disposée en trois livres, et précédée d'un prologue qui s'est substitué à l'épître dédicatoire et à la préface de VPP. Dans la mesure où VPS (encore privée de code propre dans la Bibliotheca hagiographica latina) demeure encore très proche de son modèle, l'éditrice a estimé qu'il n'était pas nécessaire de lui offrir une édition distincte. Aussi s'est-elle contentée d'indiquer en annexe de son édition de VPP les leçons propres à VPS, d'après le manuscrit $C$. 
6 L'édition proprement dite est précédée d'une introduction fournie, précise et bien renseignée, tout comme les notes qui l'accompagnent et apportent au texte un éclairage supplémentaire. Tout au plus pourrait-on signaler un lapsus, p. 21 (il faut lire « entre 936 et 942 » et non « entre 936 et 943 », puisque, comme le souligne justement l'éditrice, Odon est mort en 942, ce qui fournit à VPP un terminus ante quem assuré). Aux nombreux titres évoqués en bibliographie et en note, on pourrait aussi ajouter les références suivantes, déjà anciennes, il est vrai : P.Lamma, Momenti di storiografia cluniacense, Roma, 1961, p. 21-3 (Studi storici, fasc. 42-4), et P. Rousset, «L'idéal chevaleresque dans deux Vitae clunisiennes", dans Études de civilisation médiévale. Mélanges E. R. Labande, Poitiers, 1974, p. 623-33. L'édition elle-même est bien menée, cohérente avec le stemma codicum dressé dans l'introduction à l'aide de la méthode mise au point par Jacques Froger. À plusieurs endroits, le texte des manuscrits était corrompu, et l'éditrice a dû faire des choix. Pour l'épître dédicatoire, elle s'est ainsi ralliée au titre factice de la Bibliotheca cluniacensis (Auctoris epistola nuncupatoria), contre le titre qui figurait dans le subarchétype de la tradition manuscrite (Incipit Odonis prefatio patris amandi in uita domni illustris uirtute Geraldi). Il est probable, en effet, que le texte sorti de l'atelier d'Odon ne donnait aucun titre à cette épître ; mais il aurait alors peut-être fallu mettre entre crochets le titre reconstitué par l'éditeur de la Bibliotheca cluniacensis, certes approprié au contenu, mais nullement originel. Ces broutilles formelles ne gâtent toutefois nullement l'acribie dont fait preuve l'éditrice en maints autres endroits. Quant à la nouvelle traduction qui accompagne l'édition, elle est fidèle et fluide (en I.12, dans l'expression nec in reseruandis iniuriis tenax, on peut toutefois se demander si reseruare n'a pas plutôt le sens de " conserver le souvenir d'un dommage » plutôt que celui de «différer la poursuite d'un dommage »), attentive à restituer les realia sociales, religieuses et politiques, de la France méridionale à l'époque carolingienne. Nul doute, en tout cas, que ce volume soigné, précieux pour les médiévistes, constituera à l'avenir l'édition de référence de la Vita S. Geraldi d'Odon de Cluny.

\section{AUTEURS}

\section{CÉCILE LANÉRY}

Institut de Recherche et d'Histoire des Textes, Paris. 